\title{
2 Research Square \\ Evidence for a Pleckstrin Homology Domain-containing \\ Proteins as Novel Class of Leaderless Bacteriocins \\ Transporters
}

\section{Adrián Pérez-Ramos}

Université de Lille I: Universite de Lille Faculte des Sciences et Technologies

Abdallah Benachour

Université de Caen Basse-Normandie: Universite de Caen Normandie

Djamel Drider ( $\nabla$ djamel.drider@univ-lille1.fr )

Université de Lille I: Universite de Lille Faculte des Sciences et Technologies https://orcid.org/0000-0002-3113-1578

\section{Research Article}

Keywords: Pleckstrin Homology, Bacteriocins Transporters, spectrometry

Posted Date: August 17th, 2021

DOI: https://doi.org/10.21203/rs.3.rs-766546/v1

License: (c) (i) This work is licensed under a Creative Commons Attribution 4.0 International License. Read Full License 


\section{Abstract}

Bacteriocins biosynthetic pathway is initiated from an inactive precursor, which is composed of an N-terminal leader peptide attached to a C-terminal pro-peptide. However, leaderless bacteriocins (LLB) do not possess this N-terminal leader peptide, nor undergo post-translational modifications. These atypical bacteriocins are observed to be immediately active after their translation in the cytoplasm. However, although considered to be simple, the biosynthetic pathway of LLB remains to be fully understood. Enterocin DD14 (EntDD14) is a two-peptide LLB produced by Enterococcus faecalis 14 , a strain isolated from meconium. In silico analysis of DNA encoding EntDD14 located a cluster of 10 genes $d d A B C D E F G H I J$, where $d d E$ and $d d F$ encode the peculiar DdE and DdF proteins, carrying pleckstrin homology $(\mathrm{PH})$ domains. These modules are quite common in Eucarya proteins and are known to be involved in intracellular signalling or cytoskeleton organization. To elucidate their role within the EntDD14 genetic determinant, we constructed deletion mutants of the 2 corresponding genes. As a result, the $d d E$ or $d d F$ mutants are unable to externalize EntDD14 outside of the cytoplasm, even though there was clear expression of structural genes $d d A B$ encoding EntDD14, and genes $d d H I J$ encoding an ABC transporter. Importantly, in these mutant strains (DddE and DddF), EntDD14 was detected by mass spectrometry in the intracellular soluble fraction exerting, upon its accumulation, a toxic effect on the producing strain as revealed by cell-counting and confocal microscopy analysis. Taken together, these results clearly indicate that $\mathrm{PH}$ domain-containing proteins, like DdE and DdF, are acting as transporters of the leaderless two-peptide EntDD14.

\section{Introduction}

Bacteriocins are produced by a wide range of Gram-negative bacteria (GNB), Gram-positive bacteria (GPB) bacteria and Archaea $[1,3]$ permitting them to compete with congeners and thrive in their ecological niches. Of note, bacteriocins produced by GNB bacteria (named microcins), and those produced by GPB bacteria have been intensively studied and have shown similarities in their biosynthetic pathways and differences in their modes of action $[4,5]$.

Due to the increasing number of bacteriocins discovered, their classification is regularly revised and updated. The most recent revision proposes the inclusion of bacteriocins from both GPB and GNB bacteria into two main classes [6]. Briefly, class I contains bacteriocins with a molecular weight of less than $5 \mathrm{kDa}$, and undergoing post-translational modifications (PTMs), while class II comprises principally unmodified bacteriocins of 6-10 kDa, including or not stabilizing disulphide bridges [6].

Bacteriocins are known to be synthesized as inactive pre-peptides that undergo a maturation process, proceeding to fully active peptides. Notably, the precursor peptide carries an $\mathrm{N}$-terminal leader region, and C-terminal core region, which is subjected to enzymatic PTMs, leading therefore to post-translationally modified peptides (RiPPs) ${ }^{7}$. The leader peptide is often cut off at a double-glycine proteolytic processing site during export by an ATP-binding cassette (ABC) transporter and the mature peptide is released into the external environment. The cleavage of the leader peptide can be performed by the same ABC transporter (SunT-type transporter), or by an associated protein (NisT-type) $[5,6,7,8]$. However, other bacteriocins, like enterocin $\mathrm{P}$, contain an $\mathrm{N}$-terminal sec-dependent sequence leader and follow another biosynthetic pathway, being secreted by general sec-dependent export systems [9]. Furthermore, there are bacteriocins with leaderpeptide whose transport systems remain unclassified [8].

The export of bacteriocins is tightly associated with a complex immunity machinery, since the bacteriocin-producing bacteria need to protect themselves from the toxicity of their own bacteriocins. This immunity can be exerted by dedicated proteins and/or ABC transporters [10]. This is the case of NisEFG for nisin [11], or As-48EFGH for the cyclic enterocin AS-48 [12].

Netz et al. [13] reported a Staphylococcal bacteriocin named aureocin A70 that was transported without any processing, leading to the emergence of the leaderless bacteriocins (LLB) group. These atypical bacteriocins do not undergo any 
PTM or processing and are thought to be active immediately after their translation [14]. LLB aureocin A70 is thought to be externalized by a single-component $A B C$ transporter AurT [15]. A Three-component ABC transporter is involved in both transport and immunity to LLB aureocin A53, however this transporter is not the only pathway, because when removed there is still bacteriocin externalization. The uncharacterized Orf8 protein has been reported therefore to be essential for LLB aureocin A53 transport [16].

EntDD14 is a two-peptides LLB produced by Enterococcus faecalis 14 isolated from meconium [17], and its activity is essentially directed against GPB target bacteria including Clostridium perfringes, Listeria and other enterococcal strains [18]. Recent studies on EntDD14 showed that deletion of the ATP binding protein component of the putative ABC transporter, reduced by about $75 \%$ the bacteriocin externalization, and this $A B C$ transporter is not involved in any bacterial self-immunity system to our current knowledge [19].

In silico analysis of the EntDD14 operon has revealed two proteins, named DdE and DdF, which carry pleckstrin homology $(\mathrm{PH})$ domains. Of note, the $d d E$ and $d d F$ genes are located upstream of those encoding the $A B C$ transporter $d d H I J$. The $\mathrm{PH}$ domain is abundant in Eukarya, where it is associated with diverse functions, such as intracellular signalling and cytoskeletal organization $[20,21]$. The presence of the PH domain module in bacterial proteins was discovered by $\mathrm{Xu}$ et al. [22], who reported the bacterial $\mathrm{PH}$ domains, $\mathrm{PH} b 1$ and $\mathrm{PH} b 2$. Interestingly, the in-silico analysis, undertaken for this work showed that the DdE and DdF proteins may contain one or more PHb2 domains. Remarkably, deletion of $d d E$ or $d d F$ genes encoding the $\mathrm{DdE}$ or $\mathrm{DdF}$ protein, which carry $\mathrm{PH}$ domain led to a very interesting result, namely, following deletion of $d d E$ or $d d F$, the two-peptide LLB EntDD14 was no longer externalized, and its intracellular accumulation exerted a toxic effect on the bacteriocin-producing bacteria.

\section{Materials And Methods}

\section{Bacterial strains and growth conditions}

Bacteria used in this work are listed in Table 3. Enterococcus faecalis strains were routinely grown in M17 medium supplemented with $0.5 \%$ glucose (GM17), at $37^{\circ} \mathrm{C}$. Escherichia coli strains were grown in Luria-Bertani (LB) broth at $37^{\circ} \mathrm{C}$ by shaking at $160 \mathrm{rpm}$. Listeria innocua ATCC33090 strain was grown in Brain Heart Infusion (BHI) broth at $37^{\circ} \mathrm{C}$. When bacteria carried the pLT06 plasmid or its derivatives the medium was supplemented with chloramphenicol (Cm) at 10 $\mu \mathrm{g} / \mathrm{mL}$ for $E$. coli and at $15 \mu \mathrm{g} / \mathrm{mL}$ for $E$. faecalis. When bacteria carried the pAT18 plasmid or its derivates the medium was supplemented with erythromycin (Em) at $150 \mu \mathrm{g} / \mathrm{mL}$ for E. coli and E. faecalis.

\section{Construction of the $\Delta d d E$ and $\Delta d d F$ strains}

The $d d E$ and $d d F$ genes were separately deleted from the $E$. faecalis 14 chromosome by recombinant exchange with the surrounding regions of the genes, using a strategy based on the conditional replication of the pLT06 plasmid [23]. The oligonucleotides used for this purpose are listed in Table 4. The flanking regions of each gene were amplified by PCR using the DNAcr of E. faecalis 14 as template, the corresponding 1F/2R (upstream) and 3F/4R (downstream) oligonucleotide pairs and the PhusionTM High-Fidelity DNA Polymerase Mix (ThermoFisher Scientific). The 2R and 3F oligonucleotides have a region of 24 complementary nucleotides, which allowed us to amplify both fragments together, using a mixture of the two fragments as a template and the $1 \mathrm{~F} / 4 \mathrm{R}$ oligonucleotide pairs. This complementary region is the one that replaces the deleted gene in the mutant strain. Thus, 4 stop codons were inserted to avoid any undesired transcription. Final amplicons were purified from 1\% agarose gel. They as well as the pLT06 plasmid, were digested with Pstl and Ncol restriction enzymes (ThermoFisher scientific, USA) and finally ligated overnight with T4 ligase (ThermoFisher scientific, USA). The ligation mixtures were used to transform E. coli XL1-Blue by heat shock. Transformed colonies were selected on LB-agar plates supplemented with $\mathrm{Cm}$ at $10 \mu \mathrm{g} / \mathrm{mL}$ and X-gal at $80 \mu \mathrm{g} / \mathrm{mL}$. A blue positive colony of each construction was cultured to extract the pLT06: $\Delta d d E$ and pLT06: $\triangle d d F$ plasmids. These 
plasmids were confirmed by PCR and sequencing. A quantity of $0.5 \mu \mathrm{g}$ of both plasmids was used to transform $50 \mu \mathrm{L}$ of electro-competent cells of $E$. faecalis 14 by electroporation $(25 \mu \mathrm{F}, 2.5 \mathrm{kV}$ and $200 \Omega$ in pre-chilled $0.2 \mathrm{~cm}$ cuvettes). Transformed colonies were selected on M17-agar plates supplemented with $\mathrm{Cm}$ at $15 \mu \mathrm{g} \cdot \mathrm{mL}-1$ and X-gal at $80 \mu \mathrm{g} / \mathrm{mL}$ at $30^{\circ} \mathrm{C}$.

The first recombinant event was induced as follows. Transformant strains harbouring pLT06: $\triangle d d E$ and pLT06: $\triangle d d F$ were grown in GM17 broth supplemented with $\mathrm{Cm}$ at $15 \mu \mathrm{g} / \mathrm{mL}$ at $30^{\circ} \mathrm{C}$ for $2 \mathrm{~h}$ and then, they were shifted to $42^{\circ} \mathrm{C}$ for 4 h. At this temperature the replicon of the pLT06 plasmid was disabled and, with the selection pressure of the $\mathrm{Cm}$, its integration into the chromosome by recombination was forced. Larger blue colonies grown on M17-agar plates $(\mathrm{Cm}+\mathrm{X}$ gal) were verified by PCR using the outer 5F oligonucleotides with one of the oligonucleotides located on the plasmid (OriF or KS05seqR, in Table 4). One of these colonies from each mutant was subjected to the second recombinant event. The colonies were grown in $\mathrm{GM} 17$ broth in the absence of $\mathrm{Cm}$ at $30^{\circ} \mathrm{C}$. The cultures were diluted several times growing until stationary phase. At $30^{\circ} \mathrm{C}$ the replicon of pLT06 is functional, provoking the excision from the chromosome and without the antibiotic pressure the loss of the plasmid was favoured. White colonies grown in M17-agar-X-gal plates without $\mathrm{Cm}$ were screened for the mutant genotype by PCR using the outer 5F/6R oligonucleotide pairs. The suitable mutants for $d d E$ and $d d F$ gene deletions were verified by sequencing the surrounding genetic environment.

\section{Complementation of the $E$. faecalis $\Delta d d F$ mutant strain}

To complement the $\Delta d d F$ mutant strain, the gene $d d F$ was cloned into the pAT18 plasmid ${ }^{26}$. The DNA fragment containing $d d F$ gene was amplified by PCR using the ddF Comp oligonucleotides (Table 4). The amplicon and the pAT18 plasmid were digested with $\mathrm{Kpnl}$ and BamHI restriction enzymes and ligated overnight with the T4 ligase. The ligation mixture was used to transform E. coli XL1-Blue by heat shock. Transformed colonies were selected on LB-agar plates supplemented with Em at $150 \mu \mathrm{g} / \mathrm{mL}$ and X-gal at $80 \mu \mathrm{g} / \mathrm{mL}$. A white positive colony of each construction was cultured to extract the pAT18:ddF plasmid. This plasmid was confirmed by PCR and sequencing. Thus, $0.5 \mu \mathrm{g}$ of the plasmid was used to transform $50 \mu \mathrm{L}$ of electro-competent cells of $E$. faecalis $14 \Delta d d F$ strain by electroporation $(25 \mu \mathrm{F}, 2.5 \mathrm{kV}$ and $200 \Omega$ in pre-chilled $0.2 \mathrm{~cm}$ cuvettes). Transformed colonies were selected on M17-agar plates supplemented with Em at $150 \mu \mathrm{g} / \mathrm{mL}$ and X-gal at $80 \mu \mathrm{g} / \mathrm{mL}$. The expression of the $d d F$ gene was induced adding $0.5 \mathrm{mM}$ IPTG to the medium.

To test the antibacterial activity of the complemented strain, the Em of the medium must be removed. Nonetheless, we performed a plasmid stability study to analyse the presence of the plasmid over time. Thus, the complemented strain was cultured during 10 and 30 generations in GM17 without Em. At these points, the percentage of cells harbouring the plasmid was calculated by counting the UFC/mL on M17 agar plates containing or not Em at $150 \mu \mathrm{g} / \mathrm{mL}$.

\section{Antimicrobial activity against $L$. innocua}

The screening of Anti-L. innocua activity assays of the cell-free supernatant from E. faecalis 14 WT and mutant strains, as well as purified EntDD14 were performed using the well-known diffusion method ${ }^{18}$. Briefly, a uniform layer of Listeria culture was deposited on a soft BHI-agar (1\%) plate using a swab. Then, wells of $5 \mathrm{~mm}$ diameter were aseptically made in the agar. After that, $50 \mu \mathrm{L}$ of cell-free and/or purified EntDD14 were introduced, separately, into the wells. Then the plates were incubated at $4^{\circ} \mathrm{C}$ for $1 \mathrm{~h}$ and overnight at $37^{\circ} \mathrm{C}$. The absence or presence of inhibitory zones around the wells was recorded.

\section{RNA isolation and RT-qPCR}

Quantitative reverse transcription PCR (RT-qPCR) analysis was carried out to study the expression of genes involved in enterocin DD14 production and transport in E. faecalis 14 wild-type and $\Delta d d E$ and $\Delta d d F$ strains. At $5 \mathrm{~h}$ and $24 \mathrm{~h}$ cultures of these strains were performed. Cells were harvested by centrifugation $\left(10,000 \times \mathrm{g}\right.$ during $10 \mathrm{~min}$ at $\left.4^{\circ} \mathrm{C}\right)$ and total RNA 
was extracted using the NucleoSpin ${ }^{\mathrm{TM}}$ RNA Plus columns (Macherey-Nagel, Hoerdt, France). The quantity and quality of RNA samples were determined by capillary electrophoresis, using an Agilent 2100 Bioanalyzer (Agilent Technologies, France) and a minimal RNA integrity number (RIN) of 8 was required for all samples. $1 \mu \mathrm{g}$ of total RNA from each sample was treated with DNase (Thermo Fisher Scientific) to remove all traces of DNA. After DNase inactivation with EDTA (Thermo Fisher Scientific), the RNA was converted to complementary DNA (cDNA) using the RevertAid H Minus First Strand cDNA Synthesis Kit (Thermo Fisher Scientific). Changes in mRNA expression of several genes ( $d d A, d d B$, $d d E, d d F, d d H, d d l$ and $d d J$ ) were monitored by real-time qPCR, performed with the Brilliant III SYBR Green QPCR Master Mix (Agilent Technologies) on a "CFX Connect Real-Time PCR Detection System" thermocycler (BIO-RAD). The oligonucleotides used are listed in Table 4. The mean CT of each sample was normalized against the housekeeping gene (gyrase) and the corresponding control. The relative quantification of each gene was calculated by the $2^{-}$ $(\triangle \Delta C \mathrm{t})$ method, using the Bio-Rad's CFX Manager software.

\section{Intracellular protein extraction}

Overnight cultures of $E$. faecalis 14 strains (WT, $\Delta b a c, \Delta d d E, \Delta d d F$ and $\Delta d d F$-Comp) were diluted in fresh GM17 medium and grown at $37^{\circ} \mathrm{C}$ for $24 \mathrm{~h}$. then, the cells were harvested by centrifugation $\left(10,000 \times \mathrm{g}\right.$ during 10 min at $\left.4^{\circ} \mathrm{C}\right)$ and resuspended in lysis buffer $(20 \mathrm{mM}$ Tris- $\mathrm{HCl} \mathrm{pH} \mathrm{8.0,300} \mathrm{mM} \mathrm{NaCl})$ and then sonicated in an ice bath using the OmniRuptor 4000 Ultrasonic Homogenizer (OMNI International, USA). The fractions were analyzed by $20 \%$ Tricine-SDSPAGE and their concentrations were determined by the bicinchoninic acid (BCA) assay protein kit (Sigma-Aldrich, St Louis, USA), following the manufacturer's recommendations.

\section{Purification of the leaderless two-peptides EntDD14}

EntDD14 was purified from the supernatant of $E$. faecalis $14 \mathrm{WT}, \Delta d d E, \Delta d d F$ and $\Delta d d F$-Comp strains. The purification procedure was adapted from Abriouel et al. [24] as follows. Each strain was grown in $200 \mathrm{~mL}$ of GM17 at $37^{\circ} \mathrm{C}$ for $24 \mathrm{~h}$. After harvesting of the cultures by centrifugation (10,000×g during $10 \mathrm{~min}$ at $\left.4^{\circ} \mathrm{C}\right)$, the obtained cell-free supernatants were incubated at room temperature for $24 \mathrm{~h}$ with the CM Sephadex ${ }^{\circledR} \mathrm{C}-25$ resin (GE Healthcare Life Sciences) with shaking at $90 \mathrm{rpm}$. The mixture was poured into a chromatography column, where the resin was allowed to settle. Then, the resin was washed with $400 \mathrm{~mL}$ of distilled water and $200 \mathrm{~mL}$ of $0.5 \mathrm{M} \mathrm{NaCl}$. The resin-bound DD14 was then eluted with $30 \mathrm{~mL}$ of $1.5 \mathrm{M} \mathrm{NaCl}$. The solution containing DD14 was desalted by gel filtration using PD MidiTrap G-10 columns (GE), eluting with milliQ water. The pure EntDD14 was quantified using the BCA assay protein kit (Sigma-Aldrich) and then, was dried in aliquots by miVac Sample Concentrators (SP Scientific, USA) for its storage. When used, an aliquot of pure DD14 was resuspended in the appropriate volume of MilliQ water to achieve the desired concentration.

\section{Detection of EntDD14 by MALDI-TOF/MS}

EntDD14, contained both in the supernatants of the producing strains and in the protein mixtures of the intracellular extracts, was detected by matrix-assisted laser desorption ionization time-of-flight mass spectrometry (MALDI-TOF/MS). The analysis was carried out using the Autoflex Speed MALDI TOF/TOF equipment (Bruker Daltonics, Germany) and spectra were obtained using flexAnalysis software (Bruker Daltonics, Germany). When required, the samples were concentrated using Pierce ${ }^{\mathrm{TM}} \mathrm{C} 18$ tips (Thermo Scientific).

\section{Intracellular cytotoxicity assays}

To evaluate the effect of accumulated EntDD14 inside the cells in mutant strains, we examined the bacterial growth of WT, $\Delta d d E, \Delta d d F$ and $\Delta d d F$-Comp strains. Overnight cultures were diluted in fresh GM17 medium to $\mathrm{OD}_{600 \mathrm{~nm}}=0.05$ and the bacterial growth was followed by hourly measuring the $\mathrm{OD}_{600 \mathrm{~nm}}$ with a spectrophotometer (Aquoalabo, France) during $24 \mathrm{~h}$. The UFC. $\mathrm{mL}^{-1}$ were obtained by counting on M17 agar plates at 0, 2, 4, 6, 8 and $24 \mathrm{~h}$ of growth. 


\section{Confocal laser scanning microscopy}

Cultures of WT, $\Delta \mathrm{bac}, \Delta d d E, \Delta d d F$ and $\Delta d d F$-Comp strains were treated with the LIVE/DEAD ${ }^{\text {TM }}$ BacLight $^{\text {TM }}$ Bacterial Viability Kit (Thermo Fisher Scientific, The Netherlands) to analyze the viability of the bacteria at $24 \mathrm{~h}$ of growth. The staining procedure was carried out following the manufacturer's instructions. Stained bacterial solutions were imaged with a ZEISS LSM 780 confocal laser scanning microscope equipped with a 40x/1.3 oil immersion objective (Carl Zeiss Micro Imaging $\mathrm{GmbH}$, Germany). The SYTO 9 dye was excited with a laser at $488 \mathrm{~nm}$ and detected between $493-560 \mathrm{~nm}$; and the propidium iodide dye was excited at $561 \mathrm{~nm}$ and detected between $584-718 \mathrm{~nm}$. The images were acquired with the Zen software (Carl Zeiss Micro Imaging $\mathrm{GmbH}$, Germany), and analysed with the ImageJ software (National Institute of Health, United States).

\section{Bioinformatics}

The $E$. faecalis 14 genome sequence was obtained from GenBank under the accession number CP021161.1. The sequences were analysed using the Basic Local Alignment Search Tool of the National Center for Biotechnology Information (BLAST-NCBI: https://blast.ncbi.nIm.nih.gov/Blast.cgi) and the SnapGene®4.3.7 tool. The prediction of transmembrane helices in proteins was carried out with the TMHMM server v. 2.0

(http://www.cbs.dtu.dk/services/TMHMM-2.0/) [25]. The structural model predictions were obtained using the online server Iterative Threading ASSEmbly Refinement (I-Tasser: https://zhanglab.ccmb.med.umich.edu/I-TASSER/) [26, 27].

\section{Statistical Analysis}

All the results presented in this work were obtained from three independent experiments, and the data are expressed as the mean standard deviation. RT-qPCR results were statistically analyzed by one-way analysis of variance (ANOVA), followed by the Tukey's test to determine the significant differences between the variables at $P$-values $<0.05$.

\section{Results}

\section{In silico characterization of DdE and DdF proteins}

The EntDD14 cluster is composed of 10 genes: $d d A B C D E F G H I J$. Genes $d d A B$ encode the two peptides of EntDD14, while $d d H I J$ encode the $A B C$ transporter. The other remaining 5 genes, $d d C D E F G$, were allocated to proteins of unknown functions. Of note, genes $d d E F$, that encode two proteins of 141 (DdE) and 458 (DdF) amino acid residues, respectively displayed homology with proteins carrying PH domains. The BLAST tool analysis revealed the presence of the conserved protein domain family YdbT (Genbank accession COG3428), within the primary structure of the DdF protein. Remarkably, this domain is based on the uncharacterized membrane protein YdbT, that contains PHb2 (bacterial pleckstrin homology) domain, that was first described in Bacillus subtilis. In the genome of B. subtilis ssp. subtilis 168 strain, the protein $\mathrm{YdbT}$, of 493 amino acid residues is associated to heterologous antibiotic resistance (Genbank accession NP_388341.1), although no experimental evidence supported the allocation of such a function. Upstream of YdbT, we detected another PH domain-containing the protein named YdbS, of 159 amino acids, which has the conserved protein domain family YdbS (Genbank accession COG3402). The reported data from the Protein Data Bank (PDB) revealed that YdbS protein has two transmembrane (TM) domains and one $\mathrm{PH} b 2$ domain, while the YdbT protein has six TM domains and three PHb2 domains (Fig. 1a).

Of note, genes encoding homologous proteins of $\mathrm{YdbT}$ and $\mathrm{YdbS}$ were detected in the genomes of bacteria such as Staphylococcus aureus, Corynebacterium glutamicum or L. innocua (Table 1). In all these species, the two genes encoding YdbS- and YdbT-like proteins are contained in a same locus exhibiting a common transcriptional orientation, as 
is the case of $d d E$ and $d d F$ genes. Further, DdE and DdF proteins share sequence homology with B. subtilis YdbS and YdbT, respectively, though they are only $17 \%$ and $18 \%$ identical (Table 1, Fig. 1a).

According to BLAST analyses in the E. faecium L50 strain, which produces the leaderless two-peptide enterocin L50, counterparts of the DdE and DdF proteins exist, and displayed 79\% and 74\% homology to those found in the EntDD14 operon. Moreover, counterparts of these proteins were found in other enterococci strains which have homologous EntDD14 clusters as reported in a previous study [19].

To gain more insights on DdE and DdF, we analyzed in silico their secondary structure and TM domains prediction. This analysis supports the membrane localization of these proteins. Indeed, DdE contains two TM domains, whereas DdF contains six TM domains (Fig. 1b), and they seem to have similar structural organization such as YdbS and YdbT proteins of $B$. subtilis (Fig. 1a). In addition, a structural model was predicted for DdE and DdF using the I-Tasser program that utilises the resolved 3D structure of proteins deposited in the Protein Data Bank. The C-score is the confidence value for $\mathrm{I}$-Tasser modelling which is between -5 and 2 and where values $>-1.5$ are considered as a correct global topology model $[26,27]$.

This topological prediction assigns the DdE and DdF protein models scores of -4.23 and -3.08 , respectively (Fig. 1c), meaning a relatively low-confidence model. However, several proteins sharing DdE or DdF related structures are involved in translocation and transport across the membrane or belong to $A B C$ transporters, as shown in Table 2. These in silico analyses strongly predict that the DdE and DdF proteins are located in the cell membrane and would have a role in EntDD14 transport.

\section{PH domain-containing proteins DdE and DdF are essential for EntDD14 transport}

To confirm our in silico analyses, we deleted genes encoding DdE or DdF and analysed the resulting phenotype of the mutant strains. Deletion of each gene was performed by homologous recombination, using the thermosensitive vector pLT06 [23]. Of note, $E$. faecalis $14 \Delta d d E$ and $\Delta d d F$ mutant strains were obtained and their genetic backgrounds were confirmed by PCR and sequence analyses. Antibacterial assessment of cell-free supernatant (CFS) from $\Delta d d E$ or $\Delta d d F$ mutants was performed by the well-known agar diffusion test (ADT), against Listeria innocua ATCC33090 as bacterial target. Importantly, no inhibitory activity was detected, arguing the absence of EntDD14 in the CFS of the mutant strains (Fig. 2a). Therefore, each independently deleted gene entailed the total loss of antimicrobial activity. To confirm this hypothesis, MALDI-TOF/MS analysis was applied on CFS gathered from each mutant strain, as well as from the wildtype (WT). As expected, EntDD14 was not detected in the CFS from mutant strains (Fig. 2b), conversely that from the WT exhibited a typical peak of $5.2 \mathrm{kDa}$, corresponding to that of EntDD14, as previously reported by Caly et al. [18].

These independent ways of investigation enabled us to claim that abolition of DdE or DdF activity controls export from the cytoplasm of EntDD14. To strengthen this statement, trans-complementation assays were conducted upon cloning the $d d F$ gene into the Gram-positive replicative plasmid pAT18 [28]. The E. faecalis $\Delta d d F$-complemented strain was generated in the presence of erythromycin. However, the presence of the antibiotic is not compatible with the antimicrobial assay. A study of plasmid stability showed that after 10 and 30 generations without selection pressure, the number of bacteria still harbouring the pAT18:ddF recombinant-vector was $95 \%$ and $89 \%$, respectively (data not shown). Thus, we performed all the assays with the complemented strain without erythromycin selection. Following this, the $\Delta d d F$-complemented strain was able to secrete again EntDD14 into the CFS, as confirmed by the ADT (Fig. 2a), and MALDI-TOF/MS analyses (Fig. 2b).

These genetic experimental data showing that E. faecalis 14 lacking DdE or DdF protein is clearly unable to transport or translocate out of the cytoplasm EntDD14 bacteriocin reinforcing the predictions of the in silico analysis that allocated 
them a key role in the transport machinery. This surprising result suggests a new pathway in the mode of transport involving $\mathrm{PH}$ domain-containing proteins and likely also in the mode of action of the leaderless two-peptide EntDD14.

\section{Loss of DdE or DdF protein leads to overproduction of the EntDD14 operon}

To gain further insight into the EntDD14 mode of transport, a transcriptional analysis was carried out to evaluate the expression of genes involved in the production and transport of EntDD14, primarily those supposed to constitute the $\mathrm{ABC}$ transporter ( $d d H / \mathrm{J})$. This gene expression experiment was conducted at $5 \mathrm{~h}$ (end of logarithmic phase) and $24 \mathrm{~h}$ (stationary phase) of bacterial growth of the WT strain and its isogenic derivatives $\Delta d d E$ and $\Delta d d F$ mutant stains, and the results are shown in Fig. 3.

Regarding these results, all the genes tested are constitutively expressed by the WT strain, both at the end of the exponential phase and in the stationary phase $(24 \mathrm{~h})$. This means that the WT strain is accustomed to tolerating the presence of EntDD14 at a level that does not interfere with its growth or development. In other words, the WT strain must have an intrinsic level of resistance or immunity to its own bacteriocin that may be due to the balance between the production and evacuation of the enterocin as reflected in the expression of the genes constituting its operon structure.

Indeed, when this expression balance is disrupted by turning off either of the $d d E$ or $d d F$ genes, the resulting mutants react differently from the WT and we observe more disturbance at the end of the exponential phase (Fig. 3a) than in the stationary phase (Fig. 3b) but the changes go in the same direction in the two cases.

At the end of the log phase, $d d A$ and $d d B$ genes were 4.6- and 3.5-folds overexpressed in the $\triangle d d E$ mutant, and 3.6- and 3-folds in the $\Delta d d F$ mutant (Fig. 3a). For both situations, overexpression of $d d A$ and $d d B$ genes suggests that they may be influenced by the $d d E$ and $d d F$ genes which could lead, in their corresponding mutants, to an overproduction of EntDD14. Among the genes involved in its extracellular export, mainly $d d F$ of the $\triangle d d E$ mutant is clearly overexpressed (2.7-folds) but at a lower level than for the structural $d d A$ and $d d B$ genes which suggests an additional deficit in the ability to evacuate the enterocin outside the cell. As for the other genes of the ABC transporter system (ddHIJ), they are overexpressed by a factor of about 2 and mainly in the $\Delta d d E$ mutant.

This situation occurs also at the stationary phase but with lower overexpression levels and only for the $\triangle d d E$ mutant since there is even a slight down expression of $d d A B$ genes in $\triangle d d F$ mutant (Fig. 3b) and this may be due to a muchreduced metabolic activity.

These data indicate overall that (i) $d d A B$ genes, and (ii) those coding for $A B C$ transporter are expressed in the mutantstrains deprived of DdE and DdF proteins, but the cells are unable to externalize EntDD14 outside of the cytoplasm; allowing EntDD14 to accumulate inside the cells. To investigate this point, total intracellular proteins extracted from $\Delta d d E$ or $\Delta d d F$ mutant strains were analysed by MALDI-TOF/MS, and compared to those extracted from the WT and the $\triangle b a c$ mutant strain, formerly obtained by knocking-out $d d A B$ genes and characterized for its inability to produce EntDD14 [19]. In both $\Delta d d E$ and $\Delta d d F$ mutant-strains, a peak corresponding to EntDD14, with a molecular size of 5.2 $\mathrm{kDa}$ was detected (Figs. 4c, 4d, respectively). Of note, this peak was also detected in the WT but not in the $\triangle$ bac mutant strain (Figs. 4a, 4b, respectively). The intensity of the peaks was $400 \mathrm{AU}$ for WT, $1800 \mathrm{AU}$ for $\triangle d d E$ and 1,600 AU for $\triangle d d F$.

As expected, these data confirmed that EntDD14 is more accumulated in $\Delta d d E$ and $\Delta d d F$ mutant strains than the WT, arguing that these proteins have a key role in EntDD14 transport out of the cytoplasm.

\section{EntDD14 accumulated inside the cytoplasm induces cell-toxicity}


EntDD14 as above-stated accumulates inside the cell, when DdE or DdF is missing. To verify the probable deleterious effect of this accumulation, we compared the kinetic growth of the mutants and complemented strains to that of the WT strain (Fig. 5). These growth curves revealed discrepancies. The latency phase of the mutant strains is extended in the

first hours of growth, but reached the same $O_{600 \mathrm{~nm}}$ than that of the WT strain at the entrance of the stationary phase and remains constant throughout the $24 \mathrm{~h}$ of the experiment (Fig. $5 \mathrm{a}$ ). The growth rate $(\mu)$ of the mutant strain, $\Delta d d E$ was $1.06 \pm 0.06$ and that of $\Delta d d F$ was $1.08 \pm 0.07$, and does not differ from that of the WT strain, $1.16 \pm 0.05$. The complemented $\triangle d d F$-Comp strain shows the same behaviour as the WT strain, with a slightly lower growth rate, $1.01 \pm$ 0.06, which can be ascribed to the presence of the PAT18:ddF plasmid. Overall, the mutant-strains have registered a loss in cell viability (Fig. 5b). The CFU counts indicate that all strains had reached approximately the same number of viable cells at the end of the exponential phase, $\sim 3 \times 10^{9} \mathrm{CFU} \cdot \mathrm{mL}^{-1}$. However, after $24 \mathrm{~h}$ of growth, $\Delta d d E$ and $\Delta d d F$ mutant strains have registered 1 log reduction in CFU/mL compared to the WT strain, which represents a $90 \%$ loss of cell viability. The loss of cell-viability is not necessarily correlated to loss of turbidity of the bacterial culture, as cell lysis seems not to occur.

To confirm this cell-viability feature in the $\Delta d d E$ and $\Delta d d F$ mutant strains, we performed a confocal microscopy analysis using the live/dead Bacterial Viability Kit. The $\Delta d d F$ and $\Delta d d E$ mutant strains showed similar numbers of bacterial cells, but very low live/dead ratio compared to the WT and the $\Delta d d F$-complemented strains (Fig. $5 \mathrm{c}$ ), revealing abundance of bacteria with compromised membranes and uncultivable. Therefore, the overall results support that, in addition to provoke cell lysis, the intracellular accumulation of EntDD14 is deleterious in the mutant cells lacking $d d E$ or $d d F$ genes.

\section{Discussion}

The emergence of LLB has opened a new avenue in the field of bacteriocins mainly in understanding their biosynthetic pathway. These bacteriocins, which are composed of one to four peptides [14], do not undergo post-translational modifications or processing, and are thought to be immediately active after their translation in the cytoplasm. EntDD14 is used here as a model of the two-peptides LLB because of its high sequence homology with its counterparts of the same group.

Bacteriocin transport is most often mediated by Type IV-ABC transporters, which are known to expel toxic molecules out of the producing-cells $[5,8,10]$. Interestingly, this type of transporter is also involved in the transport of some LLB, like aureocin A70 [15], aureocin A53 [16], EntD14 [19], lacticin Q and lacticin Z [29, 30]. Nevertheless, the EntDD14 and aureocin $\mathrm{A} 53$ producing bacteria altered at least in one protein of the ABC transporters machinery, were able to expel only $25 \%$ of bacteriocin compared to the wild-type strain $[16,19]$, arguing the existence of alternative transport pathways.

Here we propose, for the first time in the history of bacteriocins, a transport role for two PH domain proteins, viz DdE and DdF. These proteins are dedicated to transport the two-peptide LLB EntDD14 out of the cell. This finding is based on a set of complementary data including in silico analyses, genetic experimental evidence and RT-qPCR tools as well as mass spectrometry and microscopy. The mutant strains $\Delta d d E$ and $\Delta d d F$, lacking therefore $\mathrm{DdE}$ and DdF, resulted in loss of EntDD14 transport, albeit genes ( $d d A B H I J)$ coding for EntDD14 and ABC transporter were expressed. Consequently, the bacteriocin remained trapped inside the cell, and leading finally to toxic internal activity. This data showed that LLB are indeed active inside the cytoplasm.

The deleterious effect of LLB was also reported for the lacticin Q, when its coding gene was expressed in the absence of the InqBCDEF genes [29]. Lacticin Q is a single-peptide LLB produced by Lactococcus lactis QU 5. The deletion of any of the InqCDEF genes abolished the bacteriocin production. These authors suggested that InqCD along with InqB genes could play a role of accessory proteins to the ABC transporter formed by InqEF genes [30]. It has been also reported, that 
deletion of orf8 gene in S. aureus A53 that produces another single-peptide LLB aureocin A53, enabled bacteriocin production [16]. The genetic determinants required for aureocin A53 synthesis are organized in at least four transcriptional units encoded by the 10.4-kb plasmid pRJ9. One of these units corresponds to the orf7 and orf 8 genes. Interestingly, the sequence analyses of Orf7 and Orf8 from $S$. aureus A53 and LnqC and LnqD from L. lactis QU 5 showed homology to $B$. subtilis YdbS and YdbT proteins, respectively (Table 1), and also, certain level of homology with DdE and DdF proteins from E. faecalis 14.

The presence of proteins DdE and DdF with such domains were as well encountered in different operons related to twopeptides LLB L50 produced by different E. faecium strains. In all of them, these PH domain-containing proteins are highly conserved, reaching a homology score of $74 \%$ for DdE and $78 \%$ for DdF. These findings showed that this new transport pathway based on $\mathrm{PH}$ domains-containing proteins is not unique to EntDD14, but is common to several singleand two-peptide LLB.

The predictive structure shed more light on the transport function of DdE and DdF proteins. Thus, DdE has structural similarities to proteins exerting electron transfer activity across the cell-membrane. But modelling of DdE did not explain how its $\mathrm{PH} b 2$ domain can interact in a transport function. On the other hand, the DdF protein has partly structural homology to $A B C$ transporter proteins (Table 2), which are composed of two differentiated domains. The first is a dimeric cytoplasmic nucleotide-binding domain (NBD), and the second is a homo- or heterodimeric transmembrane domain (TMD). Of note, DdF was in turn predicted with six transmembrane a-helices that concurs with the consensus organization of TMD, which most often includes two sets of six hydrophobic helices $[5,8]$. The highest structural homology of DdF was obtained with the TMD and the C39 protease domain of the PCAT1 transporter from Hungateiclostridium thermocellum [31]. This transporter belongs to the SunT-type ABC transporters, which cleaves the leader peptide prior to its translocation across the membrane [5], where the C39 domain is responsible of the specific recognition of the peptide and its cleavage. The putative $\mathrm{PH} b 2$ domains in DdF seem to conform under a similar structure to that of C39 domain, that could specifically recognise EntDD14 and facilitates its transport across the membrane.

The $\mathrm{PH}$ domain is widely encountered in Eukaryotic proteins where their sequences are not necessarily conserved. Nevertheless, all these proteins present the same folding in their structure, named the PH superfold, that is also shared with other domains such as phosphotyrosine binding (PTB) domain, Enabled/VASP homology (EVH1) domain and Ranbinding domain (RanBD). For this reason, the PH superfold was suggested as a scaffold for multiple functions [32]. The $\mathrm{PH}$ domain superfold includes proteins involved in binding to a variety of phosphoinositide and protein ligands, that mediate protein targeting to the membrane and protein interactions in signal transmission processes [33].

The $\mathrm{PH} b 2$ domain was described in exig_2160 protein from Exiguobacterium sibiricum 255-15. This protein is uncharacterized and its function remains unknown, but its structural study showed the oligomerization of the protein involving twelve monomers binding by the $\mathrm{PH} b 2$ domain [22]. Thus, we believe that the putative $\mathrm{PH} b 2$ domains in $\mathrm{DdE}$ and DdF proteins may be involved in their own interactions and/or in the recognition of EntDD14, leading to its transport across the membrane.

Here, we firmly believe that the DdE and DdF proteins, as well as their counterparts in the bacteriocin-producing bacteria, are not acting as accessory proteins as previously reported by Iwatini et al. [29], but constitute new carriers dedicated for LLB. Both DdE and DdF are simultaneously required for two-peptide LLB EntDD14 transport. Moreover, in all the YdbS/YdbT-like couple proteins reported in table 1, the genes were not found associated with ABC transporter genes, which strengthens our data, and thus allocating a transport function to DdE and DdF. Further analyses aimed to understand interactions between DdE and DdF as well as interactions between DdE and EntDD14 or DdF and EntDD14 constitute our next focus.

Page $10 / 21$ 


\section{Declarations}

Acknowledgments. The MALDI-TOF/MS profiling experiments to detect the EntDD14 were performed on the REALCAT platform (Lille University), funded by the French National Research Agency (ANR) program [ANR-11-EQPX-0037]. The authors would like to thank Dr. Paloma Lopez and Dr. Stephen W. Elson for their critical reading of the manuscript. The authors would like to thank as well Dr. Rabia Ladjouzi for his technical assistance.

Author's contributions: A.P.R., A.B., and D.D. designed research; A.P.R., performed research; A.P.R., A.B., and D.D. analyzed data; D.D., obtained financial support; A.B., provided plasmids used in this work; A.P.R., A.B., D.D. wrote and approved the paper.

Funding. This work has been supported by the CPER/FEDER grant awarded by la Région des Hauts-de-France (20162021).

Conflicts of interests. The authors declare no competing interests

Availability of data and material Not applicable

\section{References}

1 Drider, D. \& Rebuffat, S. Prokariotic antimicrobial peptides: from genes to applications. (Springer, 2011).

2 Hammami R et al (2013) Anti-infective properties of bacteriocins: an update. Cell Mol Life Sci 70: $2947-2967$.

3 Flaherty RA, Freed SD, Lee SW (2014) The wide world of ribosomally encoded bacterial peptides. PLoS Pathog. 10, e1004221.

$4 \quad$ Alvarez-Sieiro P et al. (2016) Bacteriocins of lactic acid bacteria: extending the family. Appl Microbiol Biotechnol. 100: 2939-295.

5 Beis K, Rebuffat S (2019) Multifaceted ABC transporters associated to microcin and bacteriocin export. Res. Microbiol. 170: 399-406.

6 Soltani S et al. (2021) Bacteriocins as a new generation of antimicrobials: toxicity aspects and regulations. FEMS Microbiol Rev. 8:45(1):fuaa039.

7 Ortega M,. van der Donk WA (2016) New Insights into the Biosynthetic Logic of Ribosomally Synthesized and Post-translationally Modified Peptide Natural Products. Cell Chem Biol. 23: 31-44.

$8 \quad$ Zheng S, Sonomoto K (2018) Diversified transporters and pathways for bacteriocin secretion in gram-positive bacteria. Appl Microbiol Biotechnol. 102: 4243-4253.

$9 \quad$ Cintas LM et al. (1997) Biochemical and genetic characterization of enterocin P, a novel sec-dependent bacteriocin from Enterococcus faecium P13 with a broad antimicrobial spectrum. Appl Environ Microbiol. 63: 4321-4330

10 Smits SHJ, Schmitt L, Beis K (2020) Self-immunity to antibacterial peptides by ABC transporters. FEBS Lett. 594: 3920-3942.

11 Ra R et al (1999) Effects of gene disruptions in the nisin gene cluster of Lactococcus lactis on nisin production and producer immunity. Microbiology. 145: 1227-1233.

Page $11 / 21$ 
12 Diaz M. et al (2003) Characterization of a new operon, as-48EFGH, from the as-48 gene cluster involved in immunity to enterocin AS-48. Appl Environ Microbiol. 69: 1229-1236.

13 Netz DJ et al (2001) Molecular characterisation of aureocin A70, a multi-peptide bacteriocin isolated from Staphylococcus aureus. J Mol Biol. 311: 939-949.

14 Perez RH, Zendo T, Sonomoto K (2018) Circular and leaderless bacteriocins: biosynthesis, mode of action, applications, and prospects. Front Microbiol. 9: (2018).

15 Coelho MLV et al (2014) Immunity to the Staphylococcus aureus leaderless four-peptide bacteriocin aureocin A70 is conferred by Aurl, an integral membrane protein. Res Microbiol. 165: 50-59.

16 Nascimento JDS et al (2012) Genes involved in immunity to and secretion of aureocin A53, an atypical class II bacteriocin produced by Staphylococcus aureus A53. J Bacteriol. 194: 875-883.

17 Al Atya AK. et al (2015) Probiotic potential of Enterococcus faecalis strains isolated from meconium. Front Microbiol. 6: 227.

18 Caly DL et al (2017) The safe enterocin DD14 is a leaderless two-peptide bacteriocin with anti-Clostridium perfringens activity. Int J Antimicrob Agents. 49: 282-289.

19 Ladjouzi R et al (2020) A Leaderless Two-Peptide Bacteriocin, Enterocin DD14, Is Involved in Its Own SelfImmunity: Evidence and Insights. Front Bioeng Biotechnol. 8: 644.

20 Rebecchi MJ, Scarlata S (1998) Pleckstrin homology domains: a common fold with diverse functions. Annu. Rev. Biophys. Biomol. Struct. 27: 503-528.

21 Lemmon, M. A. \& Keleti, D. in Modular Protein Domains (eds G Cesareni, M. Gimona, M. Sudol, \& M. Yaffe) 337363 (Wiley-VCH Verlag, 2004).

22 Xu Q et al (2010) Bacterial pleckstrin homology domains: a prokaryotic origin for the PH domain. J Mol Biol. 396: $31-46$.

23. Thurlow LR, Thomas VC, Hancock LE (2009) Capsular polysaccharide production in Enterococcus faecalis and contribution of CpsF to capsule serospecificity. J. Bacteriol. 191: 6203-6210.

24. Abriouel $\mathrm{H}$ et al (2003) A simple method for semi-preparative-scale production and recovery of enterocin AS-48 derived from Enterococcus faecalis subsp. liquefaciens A-48-32. J. Microbiol. Methods. 55: 599-605.

25. Krogh A et al (2001) Predicting transmembrane protein topology with a hidden markov model: application to complete genomes. J Mol Biol. 305: 567-580..

26 Yang J, Zhang Y (2015) I-TASSER server: new development for protein structure and function predictions. Nucleic Acids Res. 43: W174-181.

27 Wang Y et al (2017) I-TASSER-MR: automated molecular replacement for distant-homology proteins using iterative fragment assembly and progressive sequence truncation. Nucleic Acids Res. 45: W429-W434.

28 Trieu-Cuot $\mathrm{P}$ et al (1991) Shuttle vectors containing a multiple cloning site and a lacZa gene for conjugal transfer of DNA from Escherichia coli to Gram-positive bacteria. Gene 102: 99-104. 
29. Iwatani S et al (2012) Identification of the genes involved in the secretion and self-immunity of lacticin Q, an unmodified leaderless bacteriocin from Lactococcus lactis QU 5. Microbiology 158: 2927-2935.

30. Iwatani S et al (2013) Bifunctional gene cluster InqBCDEF mediates bacteriocin production and immunity with differential genetic requirements. Appl Environ Microbiol. 79: 2446-2449.

31. Lin DYX., Huang S, Chen, J (2015) Crystal structures of a polypeptide processing and secretion transporter. Nature. 523: 425-430.

32. Blomberg $\mathrm{N}$ et al (1999) The PH superfold: a structural scaffold for multiple functions. Trends Biochem Sci. 24: 441-445.

33. Lemmon M. A. in Handbook of Cell Signaling (eds R. A. Bradshaw \& E. A. Dennis) Ch. 136, (Academic Press, 2010).

34 Sousa JS et al (2018) Structural basis for energy transduction by respiratory alternative complex III. Nat. Commun. 9: 1728.

35 Sun C et al. (2018) Structure of the alternative complex III in a supercomplex with cytochrome oxidase. Nature 557: 123-126.

36 Sureshan V et al (2013) Integron Gene Cassettes: A Repository of Novel Protein Folds with Distinct Interaction Sites. Plos One 8: e52934.

37 Lee CH, MacKinnon R (2017) Structures of the Human HCN1 Hyperpolarization-Activated Channel. Cell 168: 111120.e111.

38 Hohl M et al (2012) Crystal structure of a heterodimeric ABC transporter in its inward-facing conformation. Nat Struct Mol Biol. 19: 395-402.

39 Lee JY et al (2014) Structural Basis for Heavy Metal Detoxification by an Atm1-Type ABC Exporter. Science 343: 1133-1136.

40 Kumaran D et al (2009) Domain Organization in Clostridium botulinum Neurotoxin Type E Is Unique: Its Implication in Faster Translocation. J Mol Biol. 386: 233-245.

41 Rempel S et al (2020) A mycobacterial ABC transporter mediates the uptake of hydrophilic compounds. Nature 580: 409-41.

42 Nöll A et al (2017) Crystal structure and mechanistic basis of a functional homolog of the antigen transporter TAP. Proc Natl Acad Sci U.S.A 114: E438-E447.

\section{Tables}

Table 1. Protein members of the conserved protein domain families YdbS and YdbT. They are characterised to contain the bacterial Pleckstrin homology domain $\mathrm{PH} b 2$. 


\begin{tabular}{|c|c|c|c|c|c|c|}
\hline Protein & Size $e^{a}$ & Accession No & $\% 1^{b}$ & $\begin{array}{l}\% \\
P^{c}\end{array}$ & Bacteria & $\begin{array}{l}\text { Accession } \\
\text { No }\end{array}$ \\
\hline YdbS $^{d}$ & 159 & NP_388340.1 & 100 & 100 & Bacillus subtilis ssp. subtilis 168 & NC_000964.3 \\
\hline YdbS & 159 & VEH76774.1 & 68 & 79 & Bacillus licheniformis NCTC10341 & LR134392.1 \\
\hline Lin0881 & 160 & WP_003761286.1 & 40 & 58 & Listeria innocua Clip11262 & NC_003212.1 \\
\hline SA1878 & 159 & WP_001287087.1 & 23 & 43 & $\begin{array}{l}\text { Staphylococcus aureus ssp. aureus } \\
\text { N315 }\end{array}$ & NC_002745.2 \\
\hline NCgl0612 & 149 & WP_003860754.1 & 24 & 47 & $\begin{array}{l}\text { Corynebacterium glutamicum ATCC } \\
13032\end{array}$ & NC_003450.3 \\
\hline MT_RS06490 & 177 & WP_003406264.1 & 25 & 48 & Mycobacterium tuberculosis CDC1551 & NC_002755.2 \\
\hline DdE & 141 & - & 17 & 47 & Enterococcus faecalis 14 & CP021161.1 \\
\hline$Y d b T^{d}$ & 493 & NP_388341.1 & 100 & 100 & Bacillus subtilis ssp. subtilis 168 & NC_000964.3 \\
\hline YdbT & 493 & VEH76775.1 & 52 & 72 & Bacillus licheniformis NCTC10341 & LR134392.1 \\
\hline Lin0882 & 494 & WP_010990663.1 & 31 & 51 & Listeria innocua Clip11262 & NC_003212.1 \\
\hline SA1877 & 527 & WP_001294626.1 & 23 & 46 & $\begin{array}{l}\text { Staphylococcus aureus ssp. aureus } \\
\text { N315 }\end{array}$ & NC_002745.2 \\
\hline NCgl0613 & 471 & WP_011013786.1 & 17 & 45 & $\begin{array}{l}\text { Corynebacterium glutamicum ATCC } \\
13032\end{array}$ & NC_003450.3 \\
\hline MT_RS06485 & 487 & WP_003898781.1 & 17 & 38 & Mycobacterium tuberculosis CDC1551 & NC_002755.2 \\
\hline $\mathrm{DdF}$ & 458 & - & 18 & 44 & Enterococcus faecalis 14 & СР021161.1 \\
\hline
\end{tabular}

${ }^{\text {a }}$ The protein size is given in number of amino acid residues.

${ }^{b}$ Percentage of homology identical to the template.

${ }^{\mathrm{c}}$ Percentage of homology positive to the template.

${ }^{d}$ Model proteins used as template for the homology analysis.

Table 2. Proteins structurally close to DdE and DdF given by the I-TASSER program. 


\begin{tabular}{|c|c|c|c|c|c|}
\hline PDB & $\begin{array}{l}\text { TM- } \\
\text { score }^{a}\end{array}$ & Characteristic & Role & Organism & Reference \\
\hline \multicolumn{6}{|c|}{ DdE structurally close proteins } \\
\hline $6 \mathrm{fOk}$ & 0.538 & $\begin{array}{l}\text { Respiratory alternative } \\
\text { complex III }\end{array}$ & $\begin{array}{l}\text { Electron transfer } \\
\text { membrane protein }\end{array}$ & $\begin{array}{l}\text { Rhodothermus } \\
\text { marinus DSM } 4252\end{array}$ & [34] \\
\hline $6 \mathrm{btm}$ & 0.533 & $\begin{array}{l}\text { Respiratory alternative } \\
\text { complex III }\end{array}$ & $\begin{array}{l}\text { Electron transfer } \\
\text { membrane protein }\end{array}$ & $\begin{array}{l}\text { Flavobacterium } \\
\text { johnsoniae UW101 }\end{array}$ & [35] \\
\hline $3 e 0 s$ & 0.521 & Uncharacterized protein & $\begin{array}{l}\text { Structural } \\
\text { genomics/unknown } \\
\text { function }\end{array}$ & $\begin{array}{l}\text { Chlorobaculum } \\
\text { tepidum }\end{array}$ & unpublished \\
\hline 3jrt & 0.518 & $\begin{array}{l}\text { Integron cassette protein } \\
\text { Vpc_cass } 2\end{array}$ & $\begin{array}{l}\text { Structural } \\
\text { genomics/unknown } \\
\text { function }\end{array}$ & Vibrio paracholerae & [36] \\
\hline $7 \mathrm{~d} 3 \mathrm{e}$ & 0.511 & $\begin{array}{l}\text { DUOX1-DUOXA1 in low- } \\
\text { calcium state }\end{array}$ & Electron transport & Homo sapiens & unpublished \\
\hline $5 u 60$ & 0.507 & $\begin{array}{l}\text { HCN1 hyperpolarization- } \\
\text { activated cyclic nucleotide- } \\
\text { gated ion channel }\end{array}$ & Transport protein & Homo sapiens & [37] \\
\hline
\end{tabular}

DdF structurally close proteins

\begin{tabular}{|c|c|c|c|c|c|}
\hline 4 ry2 & 0.712 & $\begin{array}{l}\text { Peptidase-containing ABC } \\
\text { transporter PCAT1 }\end{array}$ & $\begin{array}{l}\text { Transport } \\
\text { protein/hydrolase }\end{array}$ & $\begin{array}{l}\text { Hungateiclostridium } \\
\text { thermocellum ATCC } \\
27405\end{array}$ & [29] \\
\hline $3 q f 4$ & 0.434 & $\begin{array}{l}\text { Heterodimeric ABC } \\
\text { transporter }\end{array}$ & Transport protein & $\begin{array}{l}\text { Thermotoga } \\
\text { maritima }\end{array}$ & [38] \\
\hline $4 \mathrm{mrn}$ & 0.433 & $\begin{array}{l}\text { bacterial Atm1-family ABC } \\
\text { transporter }\end{array}$ & Transport protein & $\begin{array}{l}\text { Novosphingobium } \\
\text { aromaticivorans } \\
\text { DSM } 12444\end{array}$ & [39] \\
\hline $3 f f z$ & 0.423 & $\begin{array}{l}\text { Domain organization in } \\
\text { butulinum neurotoxin type } E\end{array}$ & Hydrolase/translocation & $\begin{array}{l}\text { Clostridium } \\
\text { botulinum }\end{array}$ & [40] \\
\hline 6 tqe & 0.413 & ABC transporter Rv1819c & Transport protein & $\begin{array}{l}\text { Mycobacterium } \\
\text { tuberculosis }\end{array}$ & [41] \\
\hline $5 \mathrm{mkk} 1$ & 0.407 & $\begin{array}{l}\text { Heterodimeric } A B C \\
\text { transporter TmrAB }\end{array}$ & Transport protein & $\begin{array}{l}\text { Thermus } \\
\text { thermophilus HB27 }\end{array}$ & [42] \\
\hline
\end{tabular}

${ }^{\mathrm{a}} \mathrm{TM}$-score assesses the topological similarity of protein structures. Values are between 0 and 1 . A score higher than 0.5 indicates generally the same fold in SCOP/CATH.

Table 3. List of the bacteria used in this work. 


\section{Escherichia}

coli

\begin{tabular}{|c|c|c|c|c|}
\hline XL1-Blue & - & - & Plasmid-free type strain used for plasmid cloning & $\begin{array}{l}\text { Agilent } \\
\text { Technologies }\end{array}$ \\
\hline $\begin{array}{l}\text { XL1- } \\
\text { Blue[plT06] }\end{array}$ & pLT06 & $\mathrm{Cm}^{\mathrm{R}}$ & $\begin{array}{l}\text { Source of the pLT06 plasmid used for mutant } \\
\text { strategies }\end{array}$ & [19] \\
\hline $\begin{array}{l}\text { XL1-Blue } \\
\text { [pLT06: } \Delta d d E]\end{array}$ & $\mathrm{pLT06: \Delta ddE}$ & $\mathrm{Cm}^{\mathrm{R}}$ & $\begin{array}{l}\text { Derivative of pLT06 by cloning of a } x \mathrm{pb} \text { DNA } \\
\text { fragment harbouring flanked regions of } d d E \text { gene }\end{array}$ & This study \\
\hline $\begin{array}{l}\text { XL1-Blue } \\
\text { [pLT06: } \Delta d d F]\end{array}$ & pLT06: $\Delta d d F$ & $\mathrm{Cm}^{\mathrm{R}}$ & $\begin{array}{l}\text { Derivative of pLT06 by cloning of a } x \mathrm{pb} \text { DNA } \\
\text { fragment harbouring flanked regions of } d d F \text { gene }\end{array}$ & This study \\
\hline $\begin{array}{l}\text { XL1- } \\
\text { Blue[pAT18] }\end{array}$ & pAT18 & $\mathrm{Em}^{\mathrm{R}}$ & $\begin{array}{l}\text { Source of pAT18 used for complementation studies, } \\
\text { based on the inducible lac promoter }\end{array}$ & [19] \\
\hline $\begin{array}{l}\text { XL1-Blue } \\
\text { [pAT18:ddF] }\end{array}$ & pAT18:ddF & $\mathrm{Em}^{\mathrm{R}}$ & $\begin{array}{l}\text { Derivative of pAT } 18 \text { by cloning of } d d F \text { gene under } \\
\text { the control of lac promoter }\end{array}$ & This study \\
\hline
\end{tabular}

\section{Enterococcus faecalis}

\begin{tabular}{lllll}
14 & - & - & natural strain isolated from meconium & [17] \\
\hline $14 \Delta d d E$ & - & - & deletion mutant strain of $d d E$ gene & This study \\
\hline $14 \Delta d d F$ & - & - & deletion mutant strain of $d d F$ gene & This study \\
\hline $\begin{array}{l}14 \Delta d d F- \\
\text { Comp }\end{array}$ & pAT18:ddF & $\mathrm{Em}^{\mathrm{R}}$ & $\begin{array}{l}\text { Derivative of pAT18 by cloning of } d d F \text { gene under } \\
\text { the control of lac promoter }\end{array}$ & This study \\
\hline
\end{tabular}

\section{Listeria} innocua

ATCC33090 -

Table 4. List of oligonucleotides used in this work. 


\begin{tabular}{|c|c|c|c|}
\hline ddE 1F-Pstl & ATTAAACTGCAGTGATATACAATTTATATGAACAA & \multirow{2}{*}{$\begin{array}{l}\text { Amplification } \\
\text { of } d d E \\
\text { upstream } \\
\text { fragment }\end{array}$} & \multirow[t]{2}{*}{1136} \\
\hline ddE 2R-Stop & CATTCACTAGGATCCTTAGACTTATACAAATTCATTTTTCATTGAA & & \\
\hline ddE 3F-Stop & TAAGTCTAAGGATCCTAGTGAATGAAGAAGAGGTTATTAGATGAA & \multirow{2}{*}{$\begin{array}{l}\text { Amplification } \\
\text { of } d d E \\
\text { downstream } \\
\text { fragment }\end{array}$} & \multirow[t]{2}{*}{1,107} \\
\hline ddE 4R-Ncol & ATTAAACCATGGTATCTATAGCCATAAAAATAGCC & & \\
\hline ddE 5F & AGATATATTGATATACAATTTATATG & \multirow{2}{*}{$\begin{array}{l}\text { Outer primer; } \\
\text { verification } \\
\text { of the } \\
\text { plasmid } \\
\text { integration }\end{array}$} & \multirow[t]{2}{*}{-} \\
\hline ddE 6R & ACTATCAAAATATCTCTTACATAC & & \\
\hline ddF 1F-Pstl & ATTAAACTGCAGGTCTATTATAGGAGGTAAAAATG & \multirow{2}{*}{$\begin{array}{l}\text { Amplification } \\
\text { of } d d F \\
\text { upstream } \\
\text { fragment }\end{array}$} & \multirow[t]{2}{*}{1,016} \\
\hline ddF 2R-Stop & CATTCACTAGGATCCTTAGACTTATTTCATCTAATAACCTCTTCTTTTA & & \\
\hline ddF 3F-Stop & TAAGTCTAAGGATCCTAGTGAATGTCGTAGGAGGATAGAATGAAC & \multirow{2}{*}{$\begin{array}{l}\text { Amplification } \\
\text { of } d d F \\
\text { downstream } \\
\text { fragment }\end{array}$} & \multirow[t]{2}{*}{1,027} \\
\hline ddF 4R-Ncol & ATTAAACCATGGGGCTTTTTTCATTTCATCATCC & & \\
\hline ddF $5 F$ & AAACGAAAGGGGACTGTAGC & \multirow{2}{*}{$\begin{array}{l}\text { Outer primer; } \\
\text { verification } \\
\text { of the } \\
\text { plasmid } \\
\text { integration }\end{array}$} & \multirow[t]{2}{*}{-} \\
\hline $\mathrm{ddF} 6 \mathrm{R}$ & TCAATTTTATTATCAGCTTCAGC & & \\
\hline $\begin{array}{l}\text { ddF CompF- } \\
\text { Kpnl }\end{array}$ & AAAAGGTACCAATAAAAGAAGAGGTTATTAGATG & \multirow{2}{*}{$\begin{array}{l}\text { Cloning of } \\
\text { the } d d F \text { gene } \\
\text { in pAT18 }\end{array}$} & \multirow[t]{2}{*}{1,434} \\
\hline $\begin{array}{l}\text { ddF CompR- } \\
\text { BamHI }\end{array}$ & AAAAGGATCCTGTTCATTCTATCCTCCTACG & & \\
\hline oriF & CAATAATCGCATCCGATTGCA & \multirow{2}{*}{$\begin{array}{l}\text { Cloning } \\
\text { verification } \\
\text { in pLT06 } \\
\text { plasmid }\end{array}$} & \multirow[t]{2}{*}{-} \\
\hline Ks05R & CCTATTATACCATATTTTGGAC & & \\
\hline PU & GTAAAACGACGGCCAGT & \multirow{2}{*}{$\begin{array}{l}\text { Cloning } \\
\text { verification } \\
\text { in pAT18 } \\
\text { plasmid }\end{array}$} & \multirow[t]{2}{*}{-} \\
\hline PR & CAGGAAACAGCTATGAC & & \\
\hline EntAL & ATGGGAGCAATCGCAAAAT & \multirow{2}{*}{$\begin{array}{l}\text { Amplification } \\
\text { of internal } \\
d d A \text { gene } \\
\text { fragment for } \\
\text { qPCR }\end{array}$} & \multirow[t]{2}{*}{100} \\
\hline EntAR & TAATTGCCCATCCTTCTCCA & & \\
\hline EntBL & AAAGTTTGGATGGCCATTTATT & \multirow{2}{*}{$\begin{array}{l}\text { Amplification } \\
\text { of internal } \\
d d B \text { gene } \\
\text { fragment for } \\
\text { qPCR }\end{array}$} & \multirow[t]{2}{*}{106} \\
\hline EntBR & TCAATGTCTTTTTAACCATTTTTCA & & \\
\hline EL & ACAAGAACATATACATTTGTGAAGGA & $\begin{array}{l}\text { Amplification } \\
\text { of internal } \\
d d E \text { gene }\end{array}$ & 95 \\
\hline
\end{tabular}


$\mathrm{FL}$

AGGAAAATGTTGATTTGGTGTTT

Amplification

of internal

$d d F$ gene

FR

TCCAATGAAGATAACAAGACAAAAA

fragment for

qPCR

HL TGGTCAAGAAATCAATGAAAATG

Amplification

of internal

ddHgene

HR CTAGAGATTGGGTTTGTTCTTCC

fragment for

qPCR

IL GGGATTTATCGATCGTAAGTTTG

Amplification

86

of internal

ddl gene

IR TTTTAGAAAGAATGTCATCTGCTGT

fragment for

qPCR

JL AGAAGGAGTTAAACCCGATAAGG

Amplification

87

TCATATTCTCCCAGATGTCTCAA

of internal

ddJ gene

fragment for

qPCR

\section{Figures}

A YdbS from Bacillus subtilis 168 strain

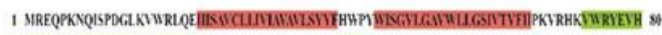

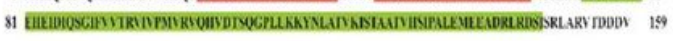

DdE from Enterococcus faecalis 14 strain

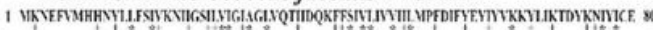

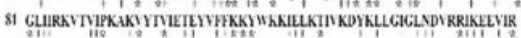

\section{YdbT from Bacillus subtilis 168 strain}

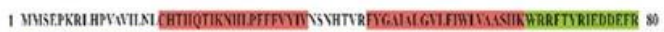

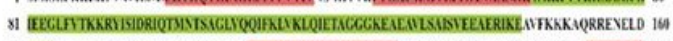

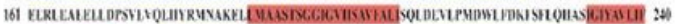

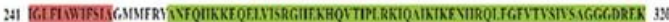

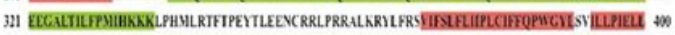

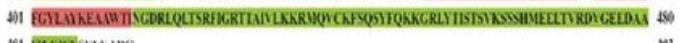

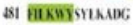

DdF from Enterococcus faecalis 14 strain

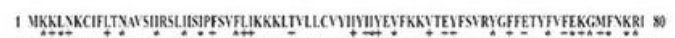

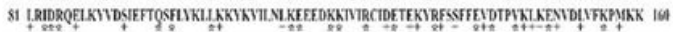
161 muss

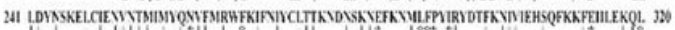

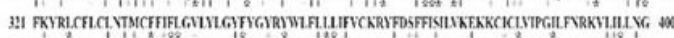

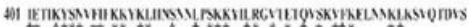

Transmembrane domain $\quad$ PIIh2 domain

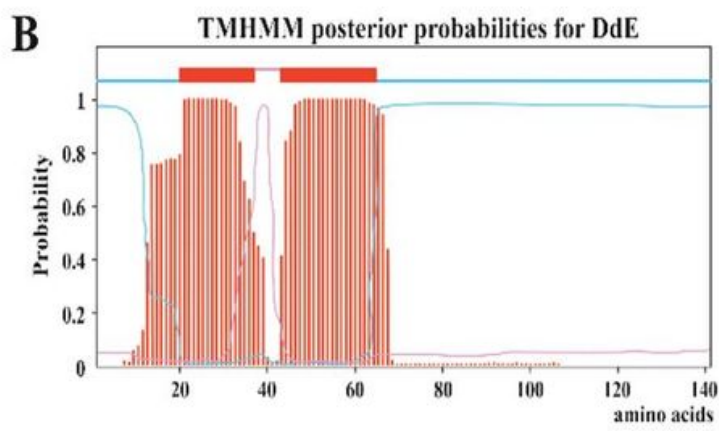

$\mathrm{C}$

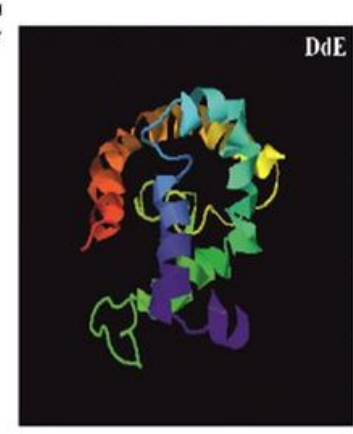

TMHMM posterior probabilities for DdF
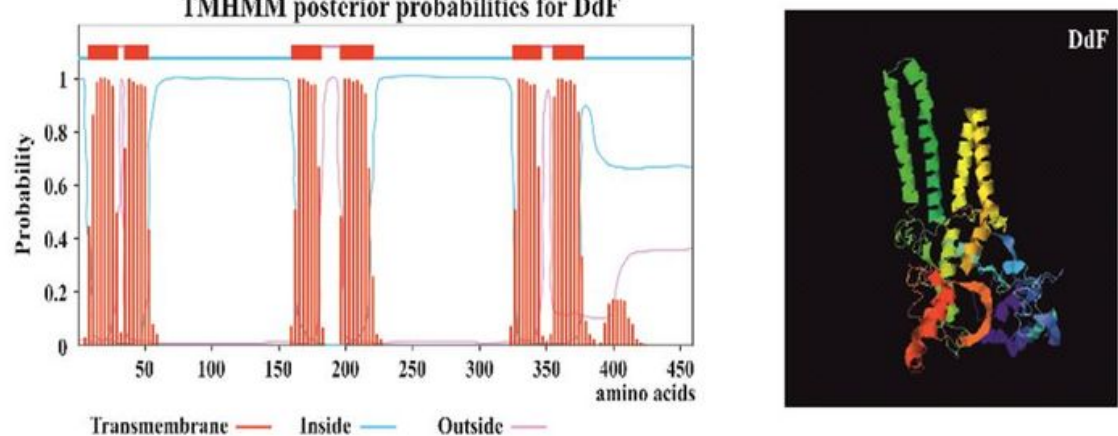

Figure 1

(A) Amino acids sequences of the YdbS and YdbT proteins, where their transmembrane and PHb2 domains are highlighted (data taken from PDB). Also, amino acids sequences of DdE and DdF proteins are depicted showing their identical (*) and positive (+) amino acid residues when aligned with YdbS and YdbT, respectively. (B) Transmembrane domains predicted for the DdE and DdF proteins. (C) Best models for DdE and DdF proposed by the I-Tasser program. 

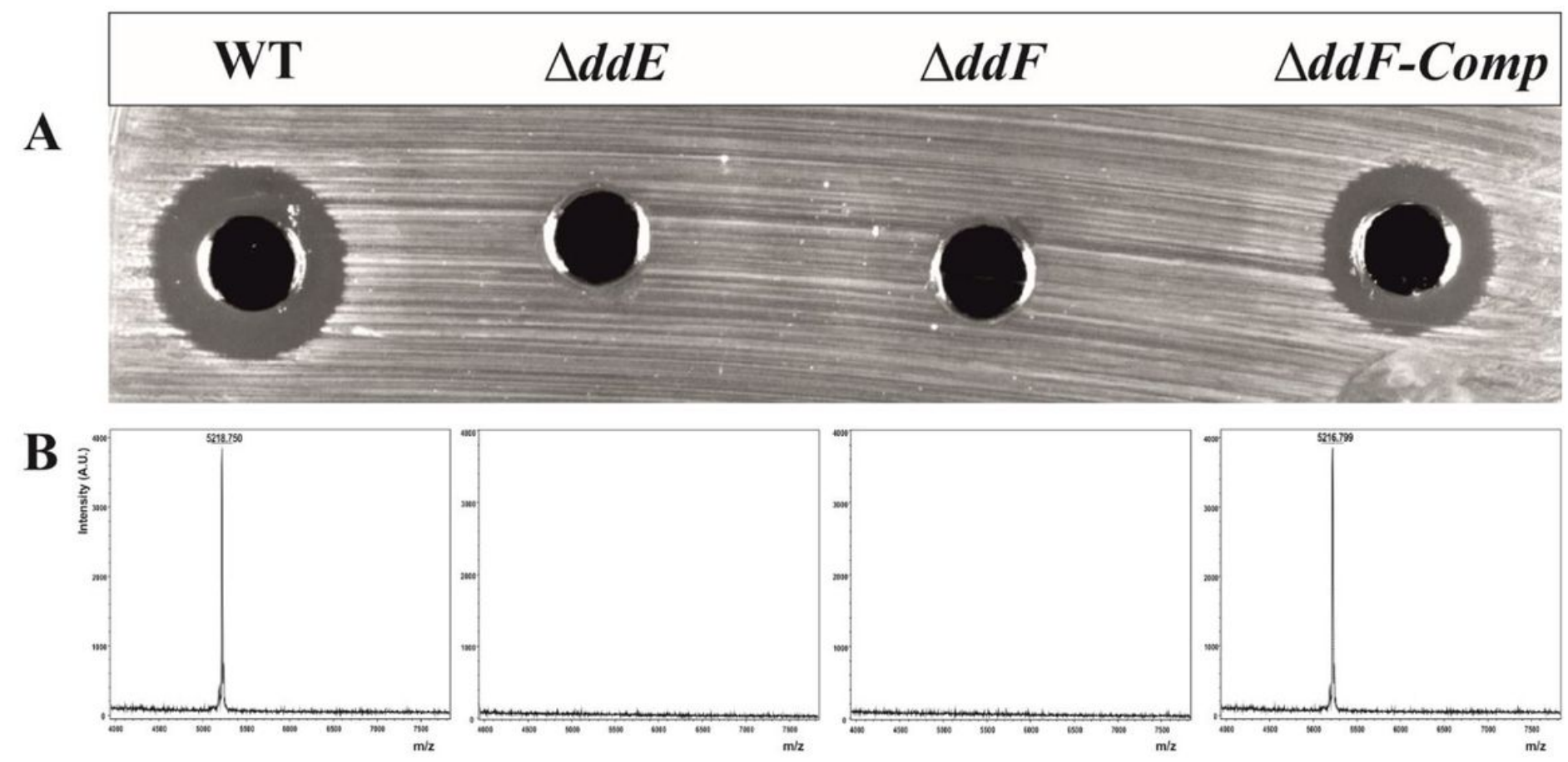

Figure 2

Production of the EntDD14 by E. faecalis 14 strains. (A) Agar diffusion test of cell-free supernatants against L. innocua ATCC33090. The inhibition halo indicates DD14 production. (B) Detection of the EntDD14 purified from bacterial supernatants by matrix-assisted laser desorption ionization time-of-flight mass spectrometry (MALDI-TOF/MS).

A

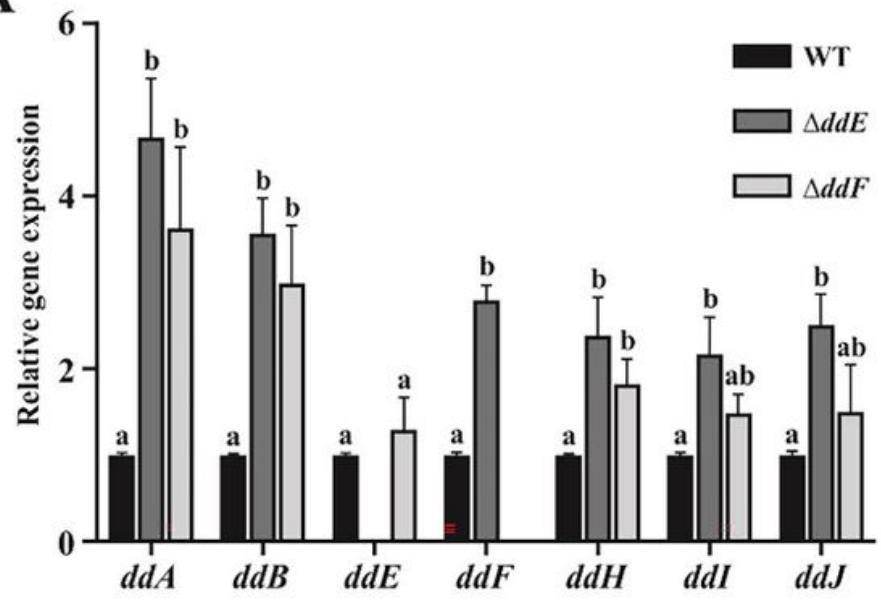

B

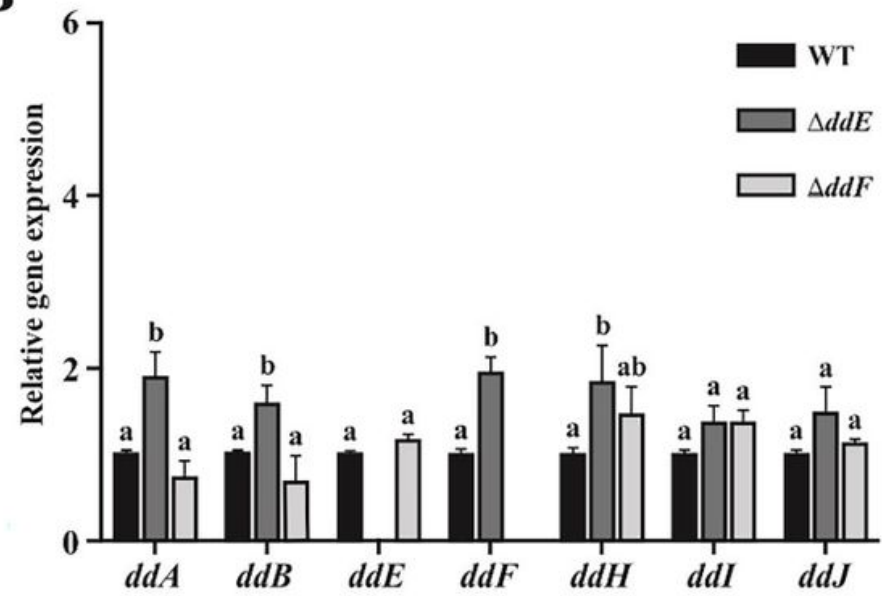

Figure 3

Relative expression values of ddABEFHIJ genes in $\triangle \mathrm{ddE}$ and $\triangle \mathrm{ddF}$ mutant stains compared to the WT strain at $5 \mathrm{~h}(\mathrm{~A})$ and $24 \mathrm{~h}(\mathrm{~B})$ of bacterial growth. The gyrase gene was used as an internal standard to normalize the values. Statistical significances are represented by letters $a$ and $b$, that mean $P<0.05$. 


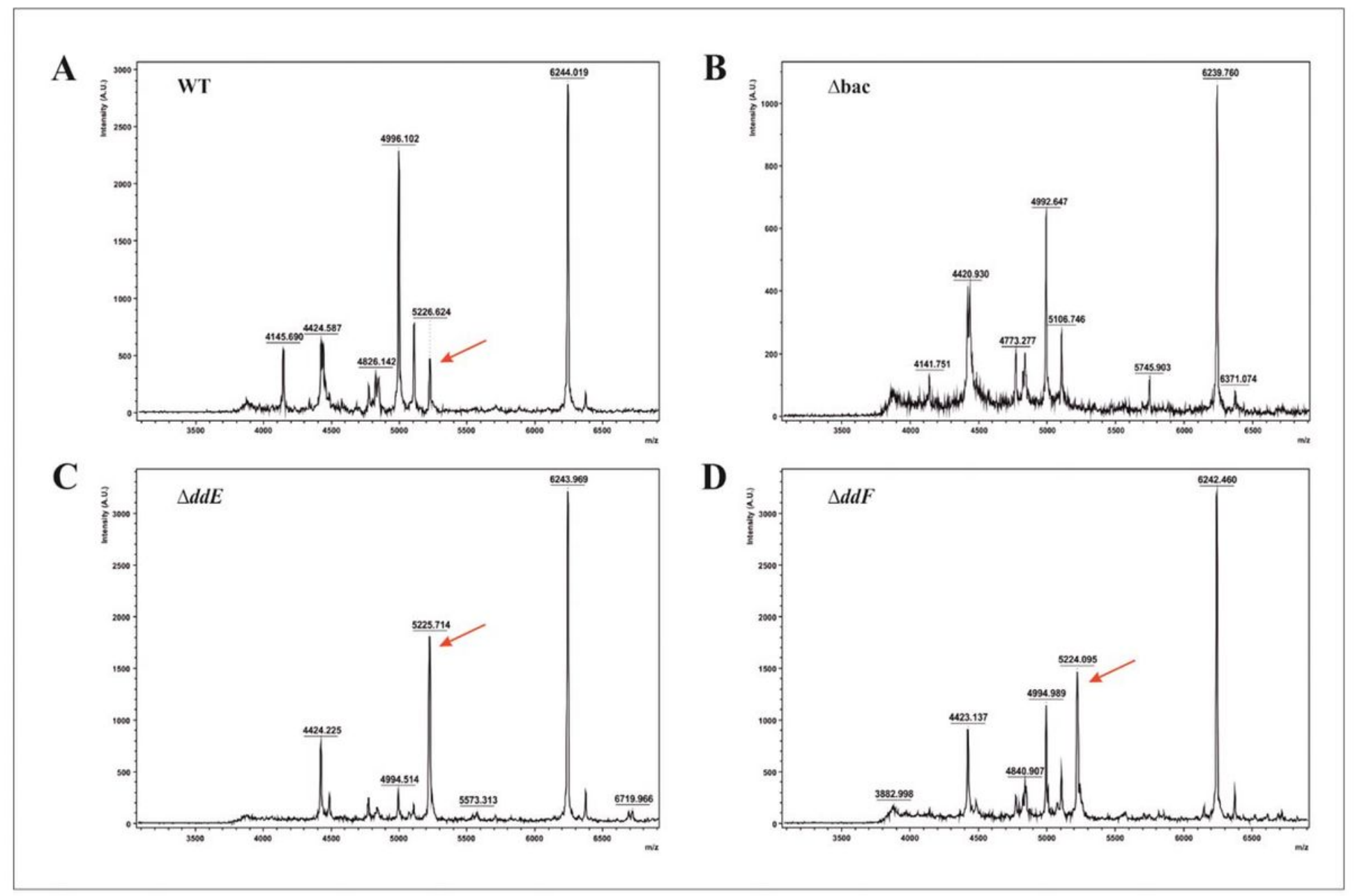

Figure 4

Matrix-assisted laser desorption ionization time-of-flight mass spectrometry (MALDI-TOF/MS) spectra obtained from intracellular fraction proteins of WT (A), $\Delta \mathrm{bac}(\mathrm{B}), \Delta \mathrm{ddE}(\mathrm{C}), \Delta \mathrm{ddF}(\mathrm{D})$ strains. Red arrows mark the peaks corresponding to the EntDD14. 


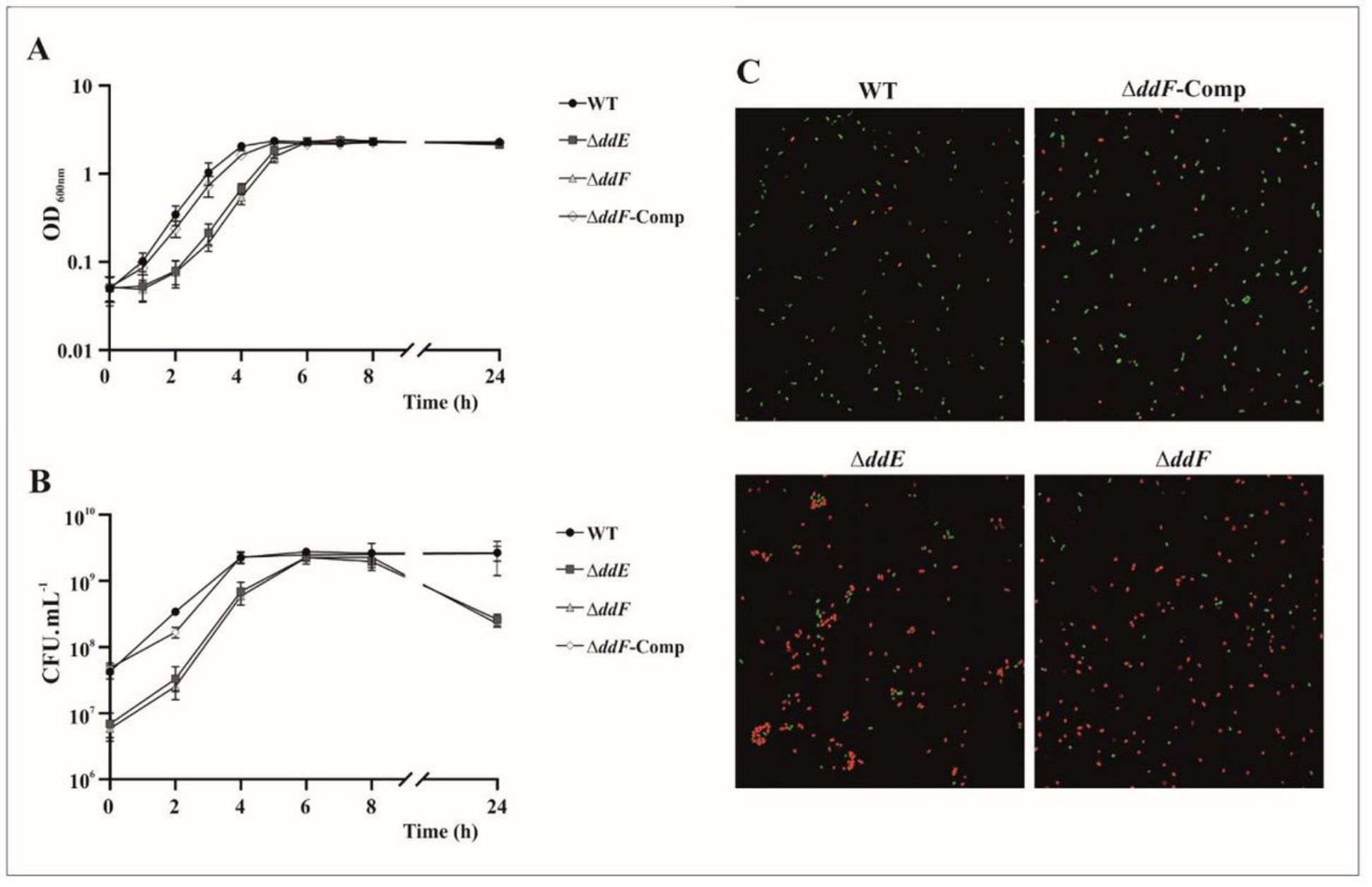

\section{Figure 5}

Analysis of bacterial growth of E. faecalis 14 strains by measuring the optical density at $600 \mathrm{~nm}(\mathrm{~A})$ and by counting the colony forming units per $\mathrm{mL}(\mathrm{B})$. (C) Confocal microscope images of bacteria stained with LIVE/DEAD viability kit, at 24 hours of bacterial growth. 